\title{
An application of Bradford's law: identification of the core journals of pediatric neurosurgery and a regional comparison of citation density
}

\author{
Garrett T. Venable • Brandon A. Shepherd • Mallory L. Roberts • \\ Douglas R. Taylor • Nickalus R. Khan • Paul Klimo Jr.
}

Received: 26 June 2014 / Accepted: 27 June 2014 / Published online: 7 August 2014

(C) Springer-Verlag Berlin Heidelberg 2014

\begin{abstract}
Purpose Bradford's law describes the number of core journals in a given field or subject and has recently been applied to neurosurgery. The objective of this study was to use currently accepted formulations of Bradford's law to identify core journals of pediatric neurosurgery. An additional analysis was completed to compare regional dependence on citation density among North American and European neurosurgeons.

Methods All original research publications from 2009 to 2013 were analyzed for the 25 top publishing pediatric neurosurgeons in North America and Europe, which were sampled to construct regional citation databases of all journal references. Regional differences were compared with each database. Egghe's formulation and the verbal formulation of Bradford's law were applied to create specific citation density zones and identify the core journals.

Results Regional comparison demonstrated a preference for the Journal of Neurosurgery and Child's Nervous System, respectively, but four of the top five journals were common to both groups. Applying the verbal formulation of Bradford's law to the North American citation database, a pattern of citation density was identified across the first three zones.
\end{abstract}

G. T. Venable $\cdot$ B. A. Shepherd $\cdot$ M. L. Roberts

College of Medicine, University of Tennessee Health Science Center,

Memphis, TN, USA

D. R. Taylor • N. R. Khan • P. Klimo Jr.

Department of Neurosurgery, University of Tennessee Health

Science Center, Memphis, TN, USA

P. Klimo Jr. $(\bowtie)$

Semmes-Murphey Neurologic and Spine Institute, 6325 Humphreys

Blvd., Memphis, TN 38120, USA

e-mail: pklimo@semmes-murphey.com

P. Klimo Jr.

Le Bonheur Neuroscience Institute, Le Bonheur Children's Hospital,

Memphis, TN, USA
Journals residing in the most highly cited first zone are presented as the core journals.

Conclusion Bradford's law can be applied to identify the core journals of neurosurgical subspecialties. While regional differences exist between the most highly cited and most frequently published in journals among North American and European pediatric neurosurgeons, there is commonality between the top five core journals in both groups.

Keywords Bradford's law $\cdot$ Bibliometrics $\cdot h$-index $\cdot$ Citation analysis $\cdot$ Core journals $\cdot$ Scopus $\cdot$ Pediatric $\cdot$ Neurosurgery

\section{Introduction}

Physicians use many resources to stay current on the latest research in their respective fields, including conferences, electronic media, periodicals, peer-reviewed journals, and textbooks [1]. Physicians have historically relied upon reading peer-reviewed journals to maintain expertise, but keeping abreast of one's field is becoming increasingly difficult, given the meteoric growth of peer-reviewed scientific literature [2]. Currently, scientific literature is reported to double every 7 years [3, 4]. Academic physicians-especially clinician researchers-face even more challenges to remain up to date on contemporary practice with increased pressure to drive cutting-edge evidence. Although pediatric neurosurgery is a relatively small discipline, some advances in this field expand upon discoveries made within other disciplines, such as molecular biology, neurology, oncology, and radiology. For this reason, it would be advantageous to identify journals that contain the highest yield of information useful to pediatric neurosurgeons.

The original description of how information is scattered for a given subject was published by Samuel C. Bradford in 1934 [5]. As a librarian in London, he discovered that for a given 
subject (he was studying geophysics), there is an exponentially diminishing return when extending a search for references in journals. If we think of all references on a given subject as being equally divided into three groups, or zones, the citations in papers in the first zone will come from a small "core" of journals. Zone 2 will involve significantly more journals to achieve the same number of citations, and the third zone will involve many more, such that there is "diminishing productivity" - or fewer and fewer references per journal-as one moves from zone 1 to zone 3 [5]. This has become known as Bradford's law of scattering, or Bradford's distribution. Hjørland and Nicolaisen [6] noted that Bradford's law has been used to influence the methodology of building collections, selecting journals indexed in bibliographies, measuring the coverage of bibliographies, solving practical problems related to information seeking and retrieval, and arguing for an updated organization of bibliographical work and scientific documentation. Together, Bradford's law of scatter, Lotka's law of scientific productivity, and Zipf's law of word occurrence form a triad of the most commonly used principles in bibliometrics.

The quantitative relationship between the zones relies upon multiple parameters in establishing a sequence of ratios often described as $c$ to $c k$ to $c k^{2}$ for the minimal three-zone pattern. Parameters $c$ and $k$ represent the number of journals in the zone 1 core and the Bradford multiplier, respectively. The parameter $p$ assigns the number of Bradford zones in the sequence and can be chosen freely but is generally accepted as a minimum of three to a maximum of ten [7]; it also sets the citation target for each zone by dividing the total number of citations, $A$, equally into $p$ zones. As an example, suppose there are six $(c)$ core journals in a given area of research (zone 1). If a researcher finds 15 articles of interest in those six journals in a month but requires an additional 12 journals to find 15 more articles of interest (zone 2), the Bradford multiplier would be $2(k)$. For each subsequent 15 articles, the scientist would have to search $24\left(c k^{2}\right)$ (zone 3), then 48 $\left(c k^{3}\right)$ (zone 4), then $96\left(c k^{4}\right)$ (zone 5) journals, and so on. It is assumed that each field has its own $c$ and $k$.

A number of mathematical approaches exist to model Bradford's law of scattering to a particular data set [7-10]. Egghe's expansion of Leimkhuler's method was employed in this study, as it has been the most widely used $[7,8,10,11]$. This formulation relies on the use of exponential functions to predict zonal distribution and depends upon the citation database parameters of total citations by the top journal and the total number of journals; however, no mathematical formulation has achieved consistent statistical significance [12].

Bradford's law of scattering has been used to describe core journals for nursing [13], physical and rehabilitation medicine [14], physical therapy [15], physics [7], occupational therapy [16], and science [9]. In 2013, Madhugiri et al. [11] described the first application of Bradford's law of distribution to identify core journals within neurosurgery. The researchers sampled all articles published within a defined 3-month period meeting criteria as stated by the authors from 11 top-ranked neurosurgical journals based on their h-index and impact factor. They were able to fit Bradford's law into three partitions $(p)$ with a total of 182 journals with the six core journals for zone 1 being the Journal of Neurosurgery, Neurosurgery, Spine, Acta Neurochirurgica, Stroke, and Journal of Neurotrauma [11].

One limitation of these results is its practical application since many neurosurgeons, private and academic, have completed fellowships and consequently have a specialized practice. A targeted approach to present core journals for each of the Committee on Advanced Subspecialty Training (CAST) neurosurgical subspecialties may be more useful to those subsets of neurosurgeons. Identifying the core journals of neurosurgical subspecialties may also serve to guide medical students, residents, and fellows to the journals that have the highest impact in subspecialties of interest.

Bradford's law was originally described for complete databases [5], but the incredible expansion of scientific literature precludes a complete sampling of broad topics, such as neurosurgery [2]. By limiting the amount of literature sampled, there will certainly be selection biases within the database. One bias may be due to regional preference of journals from which to cite it. This regional bias, to our knowledge, has not been described regarding citation bibliometrics. Neurosurgeons from Europe or Asia may choose to publish articles in regional journals and may prefer to cite articles published in those journals.

We recently created publication productivity profiles of nearly all academic neurosurgeons in the USA [17]. These bibliometric indices - the h-index in particular - have been widely applied to neurosurgery [17-25]. Using this database, we identified the 25 top-ranked North American pediatric neurosurgeons based on the manually calculated h-index from Scopus (Elsevier, www.scopus.com) [17]. By sampling the journal articles referenced by those pediatric neurosurgeons over a 5-year period (2009-2013) and applying Bradford's law, we identified the core journals of pediatric neurosurgery. In a separate analysis, we sampled articles published by a group of the top 25 pediatric neurosurgeons in Europe as provided by the Editor-in-Chief of Child's Nervous System, Dr. Concezio Di Rocco. A similar database was created for this group for relative comparison of the regional dependence on citation density and publication preference.

\section{Methods}

Study population and data retrieval

The top 25 North American academic pediatric neurosurgeons ranked by h-index were identified from our bibliometric database. All researchers carrying grants for non-pediatric- 
specific research were excluded to sample a group more representative of the general pediatric neurosurgeon. Grant history was reviewed for each author using information from departmental websites. We also analyzed 25 of the top European pediatric neurosurgeons as provided to us by Dr. Di Rocco.

Scopus was used to identify all original research journal articles for each pediatric neurosurgeon, spanning the years 2009-2013. Every article for each author was evaluated to compile data describing the journal publication counts and journal citation counts. Self-citation data were retrieved from Scopus's built-in search and filter functions.

Every effort was made in our database to exclude intradepartmental duplications of publications for those researchers who may share authorship. The researcher with the highest $\mathrm{h}$-index received credit for all publications authored. For the next highest author, any papers coauthored with the first researcher were excluded, but credit was given for all other publications. This sequence was continued until we accounted for all researchers in a given department.

After compiling the databases, we examined the citation list for entries that were not journals (e.g., book chapters and presentations), and these entries were removed. Because these nonjournal entries were removed after exportation from Scopus, the total citations used in describing the cohort are likely to be greater than the final number used in all Bradford's law analyses.

\section{Egghe's formulation of Bradford's law of distribution}

Bradford's law uses three parameters to model the $\mathrm{c}$ to ck to $\mathrm{ck}^{2} \ldots \mathrm{ck}^{\mathrm{p}-1}$ sequence using Egghe's formulation. Parameter $c$ defines the core number of journals. Parameter $k$ defines the Bradford multiplier. These parameters are dependent on the choice of $p$, which represents the number of zones. They can be solved using the equations below:

$\mathrm{k}=\left(\mathrm{e}^{\gamma} \mathrm{Y}_{\mathrm{m}}\right)^{1 / \mathrm{p}}$

$\mathrm{c}=\mathrm{T}(\mathrm{k}-1) /\left(\mathrm{k}^{\mathrm{p}}-1\right)$

The two constants in Eq. (1), e and $\gamma$, represent Euler's number and Euler's constant, respectively, where $\mathrm{e}^{\gamma}=1.781$. $\mathrm{Y}_{\mathrm{m}}$ and $\mathrm{T}$ describe qualities of the database: $\mathrm{Y}_{\mathrm{m}}$ is the number of citations of the highest ranked journal, and $\mathrm{T}$ is the cumulative number of journals in the database. Using these equations, a theoretical distribution of Bradford zones can be established for a citation database.

Egghe's formulation has been shown to be accurate for many different applications to bibliometric analyses [8]. Using Egghe's formulation, one can create a graphical representation of Bradford's distribution. The following equations are used for this:

$\mathrm{F}(\mathrm{x})=\mathrm{a} \log (1+\mathrm{bx})$

$\mathrm{a}=(\mathrm{A} / \mathrm{p}) / \log \mathrm{k}$

$\mathrm{b}=(\mathrm{k}-1) / \mathrm{c}$

Each zone of journals should contain the same number of citations $(\mathrm{A} / \mathrm{p})$ where $\mathrm{A}$ is the total number of citations. Additionally, a separate analysis based on Bradford's verbal formulation was performed; the total number of citations was separated into $p$ zones, and the number of journals in each zone was matched to the appropriate citation density. From these counts of journals, $c$ was given as the count of journals from the first zone, and $k$ was a common multiplier between zones.

\section{Analysis of regional differences in citation density}

Two separate databases were created from the North American and European groups. Databases were compared for journal publication preference, and Bradford's law was used for the final core journal analysis.

\section{Results}

Study cohort and publication database

The top 25 North American pediatric neurosurgeons were all male doctors and represented 21 separate academic departments. One department had three authors, two departments had two authors each, and 18 authors were the sole representatives from the remaining departments. The median career hindex was 37. Over the 5-year period, the mean number of publications per author was 29 , and the mean number of journal articles referenced per author was 982 . The mean number of references per publication per author was 32 . These researchers also had an average self-citation rate of 1.28 per publication (Table 1).

The top 25 European pediatric neurosurgeons, 21 of which were male doctors and 4 female doctors, represented 23 departments. Two departments had two authors, while 21 departments were represented by a single author. Their median career h-index was 15 . Over the 5-year study period, the mean number of publications per author was 22 , and the mean number of journal articles referenced per author was 583 . The mean number of references per publication per author was 26 , and the mean self-citation rate was 0.52 citations per publication (Table 1). 
Table 1 Citation metrics for the top 25 pediatric neurosurgeons
${ }^{\text {a }}$ All values reported as mean/median (range)

\begin{tabular}{lll}
\hline Citation metric $^{\mathrm{a}}$ & North America & Europe \\
\hline h-index & $39 / 37(32-56)$ & $13.96 / 15(3-31)$ \\
Years since first publication & $34.96 / 35(21-61)$ & $24.04 / 22(9-45)$ \\
Articles & $29 / 28(8-91)$ & $22 / 15(2-65)$ \\
Citations in all articles & $982 / 728(219-3353)$ & $583 / 362(42-2146)$ \\
Citations per publication & $32.02 / 30(20.38-51.85)$ & $26.08 / 24.25(10.8-41)$ \\
Self-citations per paper & $1.28 / 1.25(0.11-2.89)$ & $0.52 / 0.5(0.08-1.03)$ \\
\hline
\end{tabular}

The North American group authored 736 articles in 185 unique journals from 2009 through 2013; these articles included 23,798 total journal article references. The top ten journals that were most frequently published in were the Journal of Neurosurgery: Pediatrics (138 articles, $18.75 \%$ ), Child's Nervous System (66), Neurosurgery (43), Neurosurgical Focus (29), Epilepsia (25), Journal of Neuro-Oncology (16), Pediatric Neurosurgery (15), World Neurosurgery (15), Neuro-Oncology (14), and Journal of Neurosurgery (13). These ten journals represented over $50 \%$ of the total publications (Table 2).

The European group authored 541 articles in 168 journals from 2009 to 2013; these articles included 15,443 total journal article references. The top ten journals this group published in were the Child's Nervous System (241 articles, 37.7 \%), Journal of Neurosurgery: Pediatrics (38), Acta Neurochirurgica
(16), Neurosurgery (11), Neurocirurgia (7), British Journal of Neurosurgery (5), Journal of Neurosurgery (5), Journal of Pediatrics (5), Neurosurgical Focus (5), and World Neurosurgery (5). These ten journals also represented over $50 \%$ of the total publications for this group.

Egghe's formulation of Bradford's law

The citation database was ranked in descending order of the number of citations per journal (Table 3). The ranked citation density distribution can be seen in Fig. 1. The number of citations in the top journal, Journal of Neurosurgery, was used as $Y m(1,553)$, and the total number of journals cited was used as $T(2,231)$. Using these values in the previously described Egghe's formulation, we solved for the theoretical citation distribution for $p=3-8$, where $p$ is the number of zones.
Table 2 The top 10 journals in which the top 25 pediatric neurosurgeons published articles from 2009 through 2013

\begin{tabular}{|c|c|c|c|}
\hline Rank & Journal & Number of articles & Cumulative percent of total articles \\
\hline \multicolumn{4}{|c|}{ North America } \\
\hline 1 & Journal of Neurosurgery: Pediatrics & 138 & 18.75 \\
\hline 2 & Child's Nervous System & 66 & 27.72 \\
\hline 3 & Neurosurgery & 43 & 33.56 \\
\hline 4 & Neurosurgical Focus & 29 & 37.50 \\
\hline 5 & Epilepsia & 25 & 40.90 \\
\hline 6 & Journal of Neuro-Oncology & 16 & 43.07 \\
\hline 7 & Pediatric Neurosurgery & 15 & 45.11 \\
\hline 8 & World Neurosurgery & 15 & 47.15 \\
\hline 9 & Neuro-Oncology & 14 & 49.05 \\
\hline 10 & Journal of Neurosurgery & 13 & 50.82 \\
\hline \multicolumn{4}{|c|}{ Europe } \\
\hline 1 & Child's Nervous System & 241 & 37.71 \\
\hline 2 & Journal of Neurosurgery: Pediatrics & 38 & 44.73 \\
\hline 3 & Acta Neurochirurgica & 16 & 47.69 \\
\hline 4 & Neurosurgery & 11 & 49.72 \\
\hline 5 & Neurocirurgica & 7 & 51.02 \\
\hline 6 & British Journal of Neurosurgery & 5 & 51.94 \\
\hline 7 & Journal of Neurosurgery & 5 & 52.87 \\
\hline 8 & Journal of Pediatrics & 5 & 53.79 \\
\hline 9 & Neurosurgical Focus & 5 & 54.71 \\
\hline 10 & World Neurosurgery & 5 & 55.64 \\
\hline
\end{tabular}


Table 3 Journals ranked by the number of times of article citations within papers by the top 25 North American pediatric neurosurgeons from 2009 through 2013

\begin{tabular}{|c|c|c|c|c|c|}
\hline Rank & Journal & $\begin{array}{l}\text { Number of } \\
\text { times cited }\end{array}$ & $\begin{array}{l}\text { Cumulative percent } \\
\text { of total citations }\end{array}$ & $\begin{array}{l}\text { Bradford theoretical } \\
\text { percent of total } \\
\text { citations }\end{array}$ & $\begin{array}{l}\text { Percent difference } \\
\text { actual versus Bradford } \\
\text { theoretical }\end{array}$ \\
\hline 1 & Journal of Neurosurgery & 1,553 & 6.50 & 9.78 & 33.59 \\
\hline 2 & Neurosurgery & 995 & 10.66 & 15.23 & 30.00 \\
\hline 3 & Epilepsia & 732 & 13.72 & 19.02 & 27.85 \\
\hline 4 & Child's Nervous System & 730 & 16.77 & 21.93 & 23.50 \\
\hline 5 & Pediatric Neurosurgery & 469 & 18.74 & 24.29 & 22.87 \\
\hline 6 & Neurology & 436 & 20.56 & 26.28 & 21.77 \\
\hline 7 & Journal of Clinical Oncology & 425 & 22.34 & 28.00 & 20.22 \\
\hline 8 & Cancer Research & 411 & 24.06 & 29.51 & 18.49 \\
\hline 9 & New England Journal of Medicine & 291 & 25.27 & 30.86 & 18.11 \\
\hline 10 & Nature & 284 & 26.46 & 32.08 & 17.52 \\
\hline 11 & $\begin{array}{l}\text { Proceedings of the National Academy } \\
\text { of Sciences of USA }\end{array}$ & 275 & 27.61 & 33.19 & 16.82 \\
\hline 12 & Journal of Neurosurgery: Pediatrics & 261 & 28.70 & 34.22 & 16.11 \\
\hline 13 & Journal of Neuroscience & 252 & 29.76 & 35.16 & 15.37 \\
\hline 14 & Brain & 248 & 30.79 & 36.04 & 14.55 \\
\hline 15 & Cancer & 224 & 31.73 & 36.86 & 13.92 \\
\hline 16 & Journal of Neuro-Oncology & 213 & 32.62 & 37.63 & 13.32 \\
\hline 17 & Annals of Neurology & 212 & 33.51 & 38.36 & 12.65 \\
\hline 18 & Acta Neurochirurgica & 208 & 34.38 & 39.05 & 11.96 \\
\hline 19 & Science & 197 & 35.20 & 39.70 & 11.33 \\
\hline 20 & $\begin{array}{l}\text { International Journal of Radiation Oncology, } \\
\text { Biology, Physics }\end{array}$ & 193 & 36.01 & 40.32 & 10.69 \\
\hline 21 & American Journal of Neuroradiology & 192 & 36.81 & 40.91 & 10.02 \\
\hline 22 & Clinical Cancer Research & 188 & 37.60 & 41.48 & 9.35 \\
\hline 23 & Neurosurgical Focus & 188 & 38.39 & 42.02 & 8.64 \\
\hline 24 & Journal of Neurotrauma & 186 & 39.16 & 42.54 & 7.92 \\
\hline 25 & Surgical Neurology & 173 & 39.89 & 43.03 & 7.31 \\
\hline 26 & Neuroimage & 157 & 40.54 & 43.51 & 6.82 \\
\hline 27 & Pediatrics & 150 & 41.17 & 43.97 & 6.37 \\
\hline 28 & Journal of Biological Chemistry & 142 & 41.77 & 44.42 & 5.97 \\
\hline 29 & Neuro-Oncology & 141 & 42.36 & 44.85 & 5.56 \\
\hline 30 & Spine & 137 & 42.93 & 45.26 & 5.16 \\
\hline 31 & Acta Neuropatholologica & 130 & 43.47 & 45.67 & 4.80 \\
\hline 32 & Lancet & 126 & 44.00 & 46.06 & 4.47 \\
\hline 33 & Journal of Neurophysiology & 125 & 44.52 & 46.43 & 4.12 \\
\hline 34 & Epilepsy Research & 123 & 45.04 & 46.80 & 3.77 \\
\hline 35 & Journal of Neurology, Neurosurgery and Psychiatry & 123 & 45.55 & 47.16 & 3.41 \\
\hline 36 & Cell & 113 & 46.02 & 47.51 & 3.12 \\
\hline 37 & Blood & 109 & 46.48 & 47.84 & 2.85 \\
\hline 38 & Stroke & 109 & 46.94 & 48.17 & 2.57 \\
\hline 39 & Clinical Neurophysiology & 100 & 47.35 & 48.49 & 2.35 \\
\hline 40 & Oncogene & 100 & 47.77 & 48.81 & 2.12 \\
\hline 41 & Journal of Pediatrics & 99 & 48.19 & 49.11 & 1.88 \\
\hline 42 & Radiology & 99 & 48.60 & 49.41 & 1.64 \\
\hline 43 & Journal of Child Neurology & 96 & 49.00 & 49.70 & 1.40 \\
\hline 44 & Journal of Neuropathology and Experimental Neurology & 96 & 49.40 & 49.98 & 1.16 \\
\hline 45 & Nature Genetics & 94 & 49.80 & 50.26 & 0.93 \\
\hline
\end{tabular}


Table 3 (continued)

Rank Journal
Number of Cumulative percent times cited of total citations
Bradford theoretical Percent difference percent of total citations actual versus Bradford theoretical

\begin{tabular}{|c|c|c|c|c|c|}
\hline 46 & Pediatric Blood and Cancer & 94 & 50.19 & 50.54 & 0.68 \\
\hline 47 & Plastic and Reconstructive Surgery & 90 & 50.57 & 50.80 & 0.46 \\
\hline 48 & Neuron & 89 & 50.94 & 51.06 & 0.24 \\
\hline 49 & Journal of the American Medical Association & 84 & 51.29 & 51.32 & 0.05 \\
\hline 50 & Brain Research & 81 & 51.63 & 51.57 & -0.12 \\
\hline 51 & Cancer Cell & 81 & 51.97 & 51.81 & -0.30 \\
\hline 52 & Pediatric Neurology & 81 & 52.31 & 52.06 & -0.48 \\
\hline 53 & Critical Care Medicine & 77 & 52.63 & 52.29 & -0.64 \\
\hline 54 & Archives of Neurology & 75 & 52.94 & 52.52 & -0.80 \\
\hline 55 & British Journal of Neurosurgery & 72 & 53.24 & 52.75 & -0.93 \\
\hline 56 & Developmental Medicine and Child Neurology & 71 & 53.54 & 52.98 & -1.07 \\
\hline 57 & Neuroscience & 71 & 53.84 & 53.20 & -1.21 \\
\hline 58 & Electroencephalography and Clinical Neurophysiology & 68 & 54.12 & 53.41 & -1.33 \\
\hline 59 & Epilepsy and Behavior & 68 & 54.41 & 53.62 & -1.46 \\
\hline 60 & Genes and Development & 68 & 54.69 & 53.83 & -1.59 \\
\hline 61 & Brain Pathology & 67 & 54.97 & 54.04 & -1.72 \\
\hline 62 & Magnetic Resonance in Medicine & 61 & 55.23 & 54.24 & -1.81 \\
\hline 63 & British Journal of Cancer & 60 & 55.48 & 54.44 & -1.90 \\
\hline 64 & Journal of Clinical Endocrinology and Metabolism & 60 & 55.73 & 54.64 & -2.00 \\
\hline 65 & Plos One & 58 & 55.97 & 54.83 & -2.08 \\
\hline 66 & Clinical Neurology and Neurosurgery & 57 & 56.21 & 55.02 & -2.16 \\
\hline 67 & Neuroradiology & 56 & 56.44 & 55.21 & -2.24 \\
\hline 68 & Neurosurgical Review & 56 & 56.68 & 55.39 & -2.32 \\
\hline 69 & Cerebral Cortex & 55 & 56.91 & 55.57 & -2.40 \\
\hline 70 & IEEE Transactions on Biomedical Engineering & 55 & 57.14 & 55.75 & -2.48 \\
\hline 71 & American Journal of Medical Genetics & 54 & 57.36 & 55.93 & -2.56 \\
\hline 72 & Journal of Craniofacial Surgery & 54 & 57.59 & 56.11 & -2.65 \\
\hline 73 & Development & 53 & 57.81 & 56.28 & -2.73 \\
\hline 74 & British Journal of Haematology & 52 & 58.03 & 56.45 & -2.80 \\
\hline 75 & Experimental Neurology & 51 & 58.24 & 56.61 & -2.88 \\
\hline 76 & Human Brain Mapping & 51 & 58.46 & 56.78 & -2.95 \\
\hline 77 & Lancet Oncology & 51 & 58.67 & 56.94 & -3.03 \\
\hline 78 & Journal of Physiology & 50 & 58.88 & 57.10 & -3.11 \\
\hline 79 & Lancet Neurology & 50 & 59.09 & 57.26 & -3.19 \\
\hline 80 & Nature Reviews Neuroscience & 50 & 59.30 & 57.42 & -3.27 \\
\hline 81 & Pediatric Neuroscience & 50 & 59.51 & 57.57 & -3.35 \\
\hline 82 & Journal of Clinical Neurophysiology & 49 & 59.71 & 57.73 & -3.43 \\
\hline 83 & Archives of Disease in Childhood & 48 & 59.91 & 57.88 & -3.51 \\
\hline 84 & International Journal of Cancer & 48 & 60.11 & 58.03 & -3.59 \\
\hline 85 & American Journal of Pathology & 46 & 60.30 & 58.18 & -3.66 \\
\hline 86 & Journal of Cerebral Blood Flow and Metabolism & 46 & 60.50 & 58.32 & -3.73 \\
\hline 87 & Journal of Clinical Neuroscience & 46 & 60.69 & 58.47 & -3.80 \\
\hline 88 & Journal of Neurosurgery: Spine & 46 & 60.88 & 58.61 & -3.88 \\
\hline 89 & Nature Neuroscience & 46 & 61.07 & 58.75 & -3.95 \\
\hline 90 & Haematologica & 45 & 61.26 & 58.89 & -4.03 \\
\hline 91 & Molecular and Cellular Biology & 45 & 61.45 & 59.03 & -4.10 \\
\hline 92 & Nature Medicine & 45 & 61.64 & 59.17 & -4.18 \\
\hline
\end{tabular}


Table 3 (continued)

\begin{tabular}{llllll}
\hline Rank & Journal & $\begin{array}{l}\text { Number of } \\
\text { times cited }\end{array}$ & $\begin{array}{l}\text { Cumulative percent } \\
\text { of total citations }\end{array}$ & $\begin{array}{l}\text { Bradford theoretical } \\
\text { percent of total } \\
\text { citations }\end{array}$ & $\begin{array}{l}\text { Percent difference } \\
\text { actual versus Bradford } \\
\text { theoretical }\end{array}$ \\
\hline 93 & Pediatric Radiology & 45 & 61.83 & 59.30 & -4.26 \\
94 & Clinical Neurosurgery & 44 & 62.01 & 59.43 & -4.33 \\
95 & Journal of Neuroscience Methods & 44 & 62.20 & 59.57 & -4.41 \\
96 & Nature Reviews Cancer & 43 & 62.38 & 59.70 & -4.48 \\
97 & Human Molecular Genetics & 42 & 62.55 & 59.83 & -4.55 \\
98 & Neurosurgery Clinics of North America & 42 & 62.73 & 59.96 & -4.62 \\
99 & Acta Neurochirurgica Supplement & 41 & 62.90 & 60.08 & -4.69 \\
100 & Canadian Journal of Neurological Sciences & 41 & 63.07 & 60.21 & -4.75 \\
\hline
\end{tabular}

The citation distribution expected from Egghe's formulation did not fit the observed citation distribution identified by our citation database (Fig. 2). Egghe's formulation would predict that all zones carry an approximately equal distribution of citation density, but our distribution did not fit this expectation. With four zone distribution differences between Bradford's verbal formulation and Egghe's formulation (Table 4), Egghe's formulation was abandoned in favor of the verbal formulation of Bradford's law.

Verbal formulation of Bradford's law: North American group

Using this method, we discovered that the distribution followed a pattern for certain values of $p$. Parameters $c$ and $k$ could be found for the first three zones that satisfy the verbal formulation, while all zones beyond three failed to reach the expected citation density for that Bradford multiplier. The closest fit across the first three zones was for $p=4$ (Fig. 3). With this formula, the core journals for pediatric neurosurgery emerged as the top nine ranked journals with a Bradford multiplier of 4. The core journals of pediatric neurosurgery ranked by citation are as follows: the Journal of Neurosurgery, Neurosurgery, Epilepsia, Child's Nervous System, Pediatric Neurosurgery, Neurology, Journal of Clinical Oncology, Cancer Research, and New England Journal of Medicine.

\section{Regional differences in citation density}

A Bradford's law analysis was completed in a similar fashion for a group of 25 of the top European pediatric neurosurgeons. The citation density among this group was more closely correlated with Egghe's formulation than the North American data set (Fig. 4). For continuity between group comparisons, the final Bradford model used was the verbal formulation. The verbal

Fig. 1 Citation counts

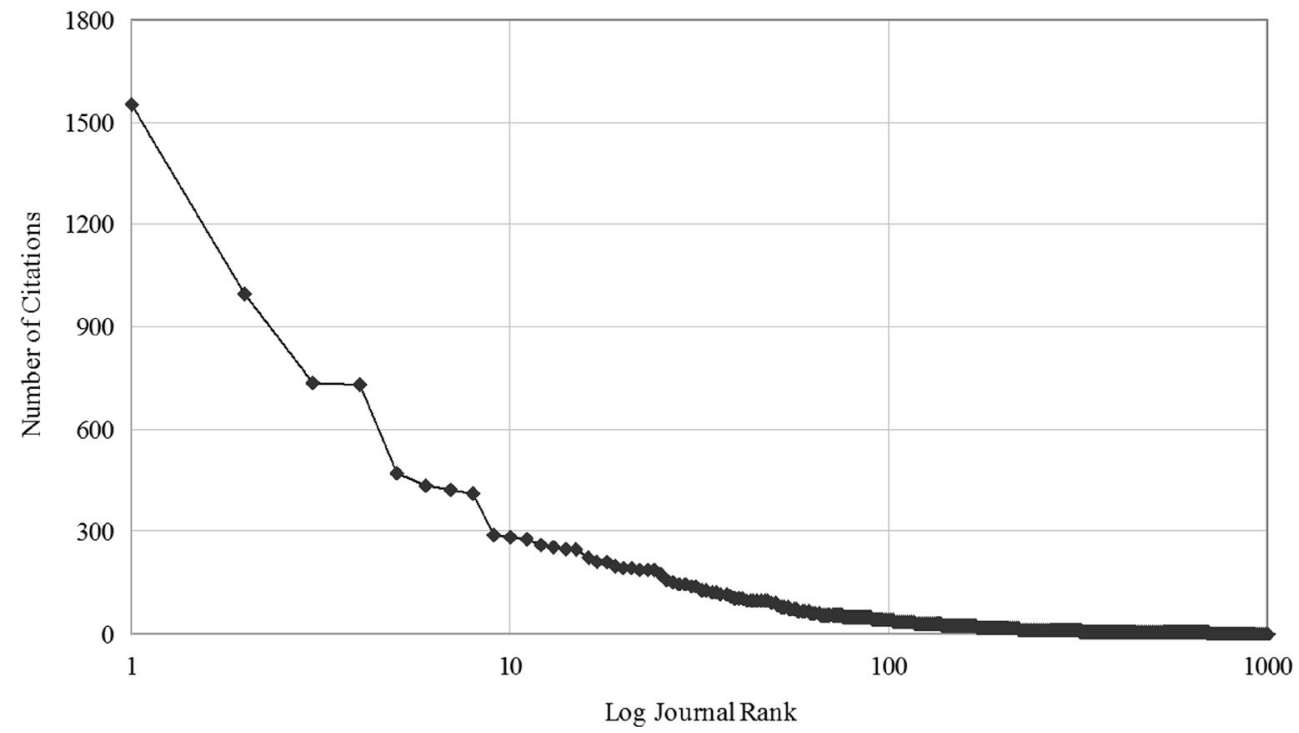


Fig. 2 Evaluation of observed data versus plot of Bradford's graphical law for North American pediatric neurosurgeons

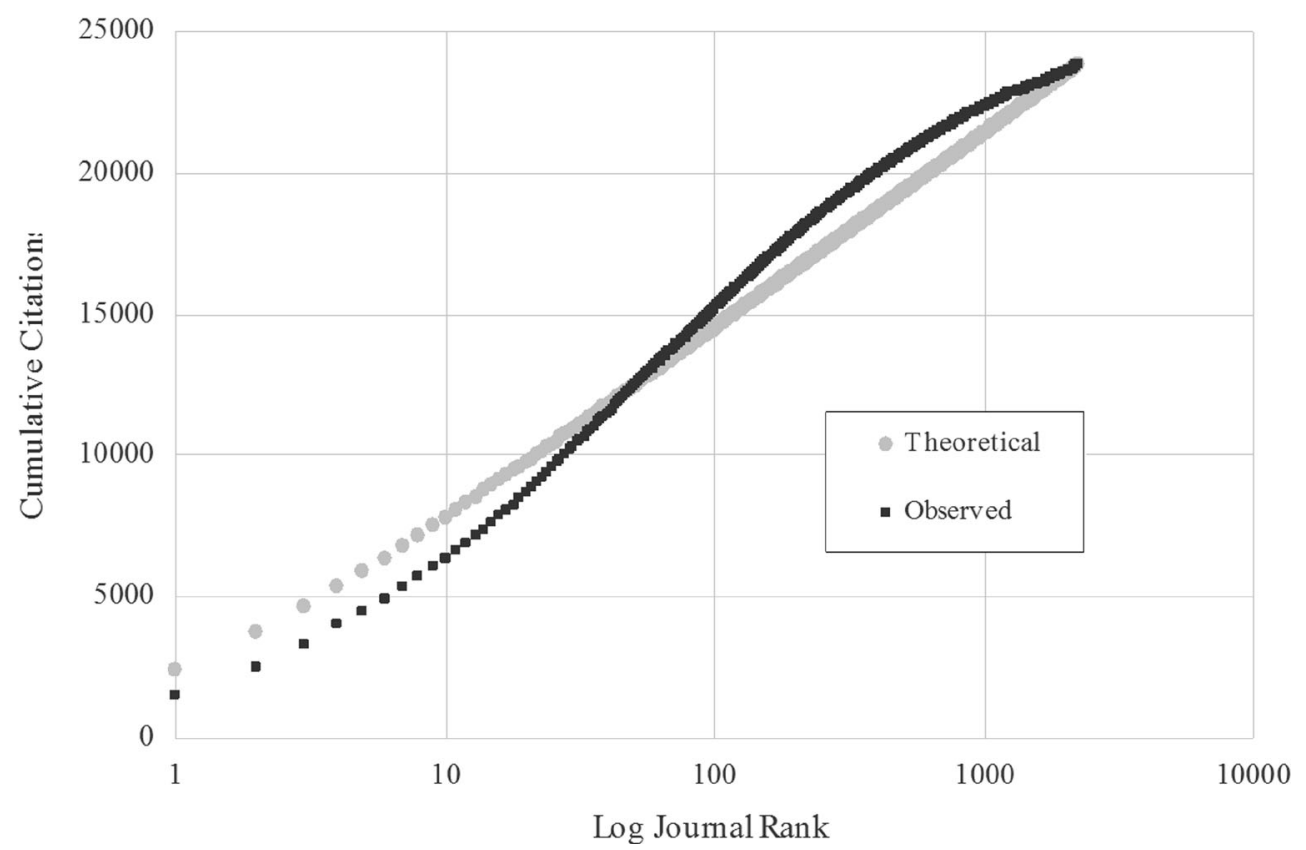

formulation of Bradford's law for the European group demonstrated five journals within the core zone. The core journals from the European database as ranked by citation count are Child's Nervous System, Journal of Neurosurgery, Neurosurgery, Pediatric Neurosurgery, and Journal of Neurosurgery: Pediatrics.

\section{Discussion}

Bradford's law, although not commonly used in academic medicine, was recently used by Madhugiri et al. [11] to identify core journals for the entire field of neurosurgery. The aim of our current study was to further establish a method of using Bradford's law in identifying core journals of pediatric neurosurgery. Using the verbal formulation of Bradford's law, we found nine journals in the core with a Bradford multiplier of 4. A separate analysis was conducted using Bradford's law to identify regional differences in citation density and preference between North American and
European pediatric neurosurgeons. To our knowledge, this is the first study, to date, analyzing regional dependence upon citation density.

Sampling for these types of analyses may be done in one of two ways; some Bradford's law analyses begin by sampling from a selection of journals specific to an academic field, while others sample the publications of a select group of researchers to analyze their core journals [7, 12]. We chose the second methodology to adequately include those journals that, although unconventional, may contain high-impact articles. The publication history of the top 25 North American pediatric neurosurgeons was chosen based on the h-index because the h-index is a measure of career productivity, and as such, these clinicians have a proven track record of highimpact articles [17, 20]. A 5-year publication history of the top 25 neurosurgeons was chosen to provide an adequate and current sample of references from which to draw meaningful conclusions. We believe that sampling the recently published research by pediatric neurosurgeons accurately portrays the distribution of the active journals in pediatric neurosurgery. Although a different methodology was used to select the
Table 4 Four-zone distribution of journals for North American pediatric neurosurgeons

${ }^{a}$ For a four-zone model $(p=4)$, the distribution of citations per zone theoretically should be 5,950 . Percent difference is reported as each formulation's difference from this value

\begin{tabular}{|c|c|c|c|c|c|c|}
\hline \multirow[b]{2}{*}{ Zone } & \multicolumn{3}{|c|}{ Bradford's verbal formulation } & \multicolumn{3}{|c|}{ Egghe's formulation } \\
\hline & $\begin{array}{l}\text { Observed } \\
\text { journals }\end{array}$ & $\begin{array}{l}\text { Observed } \\
\text { citations }\end{array}$ & $\begin{array}{l}\text { Percent difference } \\
\text { from theoretical }^{\mathrm{a}}\end{array}$ & $\begin{array}{l}\text { Theoretical } \\
\text { journals }\end{array}$ & $\begin{array}{l}\text { Observed } \\
\text { citations }\end{array}$ & $\begin{array}{l}\text { Percent difference } \\
\text { from theoretical }^{\mathrm{a}}\end{array}$ \\
\hline 1 & 9 & 6,053 & -1.73 & 5 & 4,490 & -24.54 \\
\hline 2 & 36 & 5,928 & +0.37 & 37 & 7,200 & +21.01 \\
\hline 3 & 160 & 5,944 & +0.10 & 265 & 7,557 & +27.01 \\
\hline 4 & 2,026 & 5,873 & +1.29 & 1,924 & 4,551 & -23.51 \\
\hline
\end{tabular}


Fig. 3 Citation distribution of Bradford's verbal formulation versus observed. The Bradford's distribution over four zones is depicted. The line depicts the fit of the first three zones

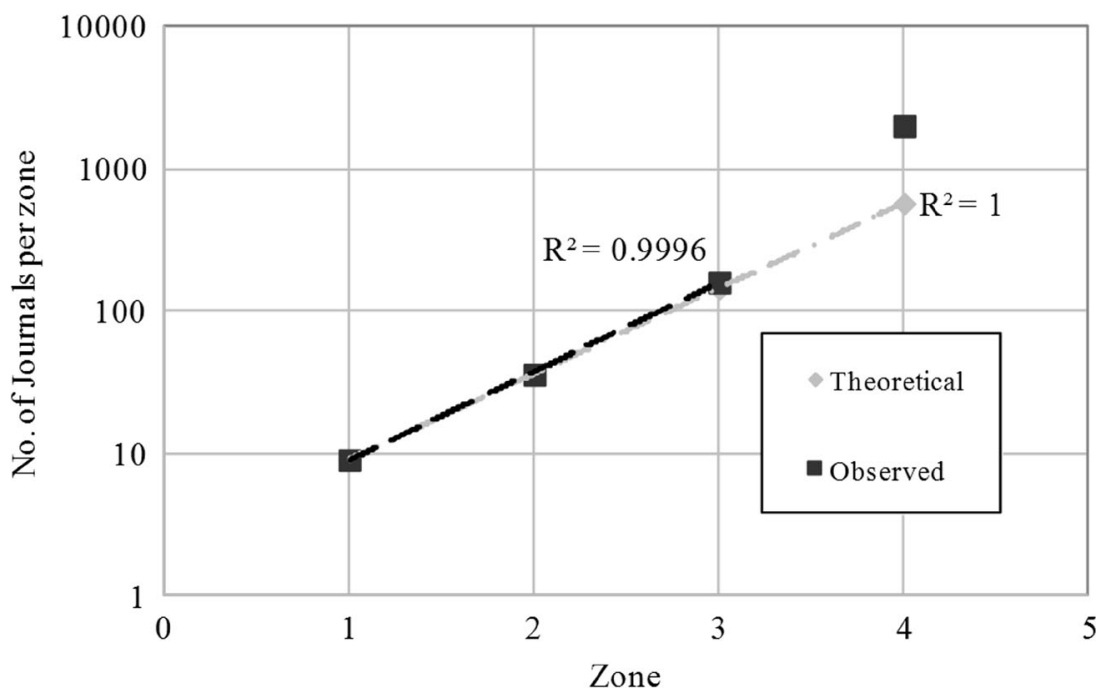

top 25 European pediatric neurosurgeons, we believe their 5-year publication history to be comparable to North American citation preferences. To our knowledge, a large bibliometric profile of European neurosurgeons has not been created, but our knowledge of European neurosurgical departments is limited.

We identified a difference between journals in which North American pediatric neurosurgeons are publishing and those that they are citing. While nearly one fifth of the articles published by North American authors appeared in the Journal of Neurosurgery: Pediatrics, it represented only $1.09 \%$ of all citations, ranking as the 12th most-cited journal and falling into zone 2 of the Bradford distribution. This finding is consistent with our previous studies. We recently demonstrated that the Journal of Neurosurgery: Pediatrics published no articles in the top 100 cited pediatric neurosurgical articles of all time but was the source of one article in the top 50 list over the last decade [26]. This journal officially split from the
Journal of Neurosurgery as a separate publication in 2004 (www.thejns.org), and in general, the impact of a journal takes time to increase.

Our citation database did not fit the currently accepted formulations of Bradford's law, an issue common to many other researchers $[6,7,11]$. The observed distribution showed a greater number of citations in the first and last zones than expected, while the central zones contained less. Analysis of European pediatric neurosurgeons illustrated a less pronounced difference.

To explain the discrepancy of our results from the expected zonal distribution, it has been suggested that highly interdisciplinary fields favor this type of distribution [12]. The concept of interdisciplinarity and its impact on the production of scientific literature has only recently been described [27]. Hjørland [12] addressed the definitions of "subject" and "interdisciplinarity" in application to Bradford's law in 2007. When a subject
Fig. 4 Evaluation of observed data versus plot of Bradford's graphical law for European pediatric neurosurgeons

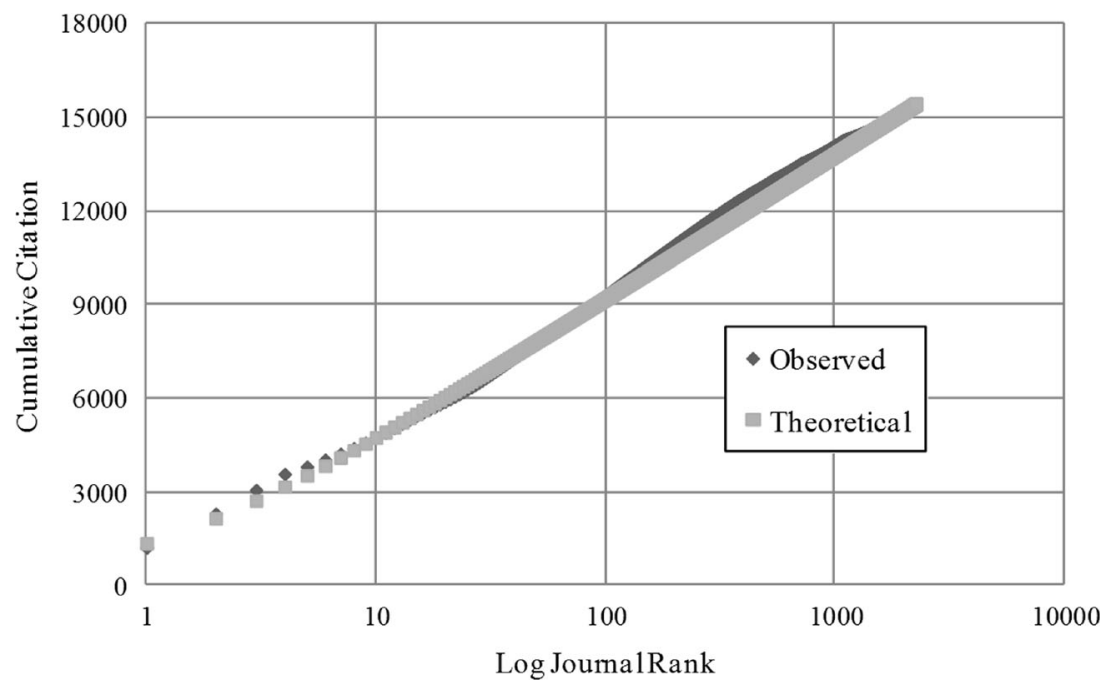


has a high degree of interdisciplinarity, the distribution of that information will likely have increased scatter. Since pediatric neurosurgery involves the integration of multiple disciplines, including the basic sciences, the relative weakness of the core and strength of the central zones compared with the theoretical model can likely be explained by this concept. Further research on interdisciplinarity and its impact on the spread of scientific information is needed.

The discrepancy in the actual data from the model may also be explained by looking at the journals that make up each zone. The core journals represent those that are more specific and inclusive to the field of study. The journals that make up the second zone represent a broader range of research and a broader readership. Many journals in this second zone also have high h-indices and impact factors. These journals may contain a small number of high-impact articles relevant to many disciplines. Analysis of specific article density per journal was outside the scope of this study.

The influence of region upon citation density or citation patterns has not been previously described. Regional biases have been studied for article inclusion within meta-analyses; a study by Egger et al. found that meta-analyses published in English-language journals almost exclusively included prior studies published in English, even though many prominent Western European journals publish in other languages [28]. Similarly, there were differences in the most frequently cited and published-in journal between North American and European pediatric neurosurgeons. The North American group favored the Journal of Neurosurgery: Pediatrics for publishing, while the Journal of Neurosurgery was the most cited; conversely, Child's Nervous System was both the most published in and the most cited journal among Europeans. While the top preference does show a regional bias when comparing the results of the Bradford analysis between groups, the top five journals between groups differed by only one journal. Child's Nervous System, Journal of Neurosurgery, Neurosurgery, and Pediatric Neurosurgery were common in both groups, while the European and North American fifth most-cited journals were the Journal of Neurosurgery: Pediatrics and Epilepsia, respectively. This similarity demonstrates that those four common journals are publishing research that is fundamental to ongoing studies on both sides of the Atlantic Ocean.

So, how does our work affect the average pediatric neurosurgeon? Given the time necessary to fulfill clinical, administrative, and family duties, one is left with limited opportunity to stay well-informed on current literature within a chosen field of expertise. It is therefore fitting to identify the most valuable journals in terms of significant articles to provide direction toward high-impact literature. We have demonstrated that there are several journals with broader readership whose research articles have a significant impact upon our small specialty. Do we recommend that one should subscribe to all journals listed in our core? No. This would be prohibitive both logistically and financially; however, a possible solution would be for pediatric neurosurgical societies (e.g., American Society of Pediatric Neurosurgeons) to periodically highlight those articles pertinent to our specialty found in those nontraditional journals. Kondziolka wrote a well-worded editorial to the article by Madhugiri et al. [29] in which he states that the classic knowledge paradigm of article submission/peer review/publication/citation is "fundamentally flawed." Indeed, there are other avenues, some driven by technology and possibly more time efficient, that allow researchers to stay up to date, apart from reading journals, such as attending conferences, participating in journal clubs, using online resources (e.g., www.uptodate.com), teaching residents and fellows, and interacting with other neurosurgeons electronically (e.g., Neurosurgery Research ListServ, www.neurosurgic.com). Some search engines (e.g., Scopus and Google Scholar) can now alert clinicians when articles that fit their areas of research are published online. ResearchGate (www.researchgate.com) is an online community of researchers that allows the subscriber to choose which other researchers within the community to follow, thereby replacing the written journal as the primary source of information with a group of individuals. Nonetheless, perusing a table of contents within the ever-growing stack of journals on one's office desk will remain an important means of acquiring new information. We believe that identifying the core journals of neurosurgical subspecialties can direct readership to the journals that are most likely to contain useful information while also identifying those journals that, although unconventional, may contain especially high-impact articles.

\section{Limitations}

This study can only be as accurate as the database used to complete it (i.e., Scopus). Scopus may have multiple entries for some researchers based on variation in name reporting. These entries generally included few or singular publications that may or may not have met our inclusion criteria and were not included in this analysis. With such a large sample size (23,798 Citations), we considered the lack of these entries to be negligible. The export utility in Scopus is limited to 160 rows of data, and thus, the inclusion criteria were broken into smaller partitions to accommodate this limitation; however, when viewing all citations used by an author, Scopus eliminates duplicate references, and by exporting smaller partitions of the whole, some of these duplications may have been included. Data collection was completed in early December 
2013 and, as such, may not have included all publication in the stated time frame.

\section{Conclusion}

Bradford's law of distribution has been underapplied to fields of academic medicine. We present the first core journal analysis of pediatric neurosurgery. There is a regional bias toward the top cited journal between North American and European pediatric neurosurgeons, but four of the top five cited journals are common to both groups. We propose that the current core journals for pediatric neurosurgery are the Journal of Neurosurgery, Neurosurgery, Epilepsia, Child's Nervous System, Pediatric Neurosurgery, Neurology, Journal of Clinical Oncology, Cancer Research, and New England Journal of Medicine.

Acknowledgments The authors would like to thank Andrew J. Gienapp, Kristin Kraus, and Shirley McCartney for their expertise in medical editing and contributions to this manuscript. Additionally, the authors would like to thank Prof. Di Rocco for providing his knowledge of the top neurosurgeons in Europe.

Conflict of interest None of the authors have any financial relationships or conflicts to disclose.

\section{References}

1. Scheckler WE (1982) A realistic journal reading plan. The cornerstone of continuing medical education. JAMA J Am Med Assoc 248: 1987-1988

2. Tenopir C, King DW, Clarke MT, Na K, Zhou X (2007) Journal reading patterns and preferences of pediatricians. J Med Libr Assoc JMLA 95:56-63

3. Tague J, Beheshti J, Rees-Potter L (1981) The law of exponential growth. Evidence, implications, and forecasts. Libr Trends 30:125-149

4. Price DJ (1965) Networks of scientific papers. Science 149:510-515

5. Bradford S (1934) Sources of information on specific subjects. Engineering 137:85-86

6. Hjørland B, Nicolaisen J (2005) Bradford's law of scattering: ambiguities in the concept of "subject". Context: nature, impact, and role. Springer, $\mathrm{p}$ 96-106

7. Sudhier KG (2010) Application of Bradford's law of scattering to the physics literature: a study of doctoral theses citations at the Indian Institute of Science. DESIDOC J Libr Inf Technol 30:3-14

8. Egghe L (1990) Applications of the theory of Bradford's law to the calculation of Leimkuhler's law and to the completion of bibliographies. J Am Soc Inf Sci 41:469-492

9. Brookes BC (1969) Bradford's law and the bibliography of science. Nature 224:953-956
10. Leimkuhler F (1967) The Bradford distribution. J Doc 23:197-207

11. Madhugiri VS, Ambekar S, Strom SF, Nanda A (2013) A technique to identify core journals for neurosurgery using citation scatter analysis and the Bradford distribution across neurosurgery journals. J Neurosurg 119:1274-1287

12. Hjorland B (2007) Practical potentials of Bradford's law: a critical examination of the received view. J Doc 63:359-377

13. Smith DR (2010) A longitudinal analysis of bibliometric and impact factor trends among the core international journals of nursing, 19772008. Int J Nurs Stud 47:1491-1499

14. Franchignoni F, Munoz Lasa S (2011) Bibliometric indicators and core journals in physical and rehabilitation medicine. J Rehabil Med Off J UEMS Eur Board Phys Rehabil Med 43:471-476

15. Fell DW, Burnham JF, Buchanan MJ, Horchen HA, Scherr JA (2011) Mapping the core journals of the physical therapy literature. J Med Libr Assoc JMLA 99:202-207

16. Smith DR (2010) Identifying a set of 'core' journals in occupational health, part 2: lists derived by bibliometric techniques. Arch Environ Occup Health 65:173-175

17. Khan NR, Thompson CJ, Taylor DR, Venable GT, Wham RM, Michael LM, 2nd, Klimo P, Jr. (2013) An analysis of publication productivity for 1225 academic neurosurgeons and 99 departments in the United States. J Neurosurg

18. Venable GT, Khan NR, Taylor DR, Thompson CJ, Michael LM, Klimo P, Jr. (2013) A correlation between NIH funding and bibliometrics in neurosurgery. World Neurosurg

19. Khan N, Thompson CJ, Choudhri AF, Boop FA, Klimo P Jr (2013) Part I: the application of the h-index to groups of individuals and departments in academic neurosurgery. World Neurosurg 80(759765):e753

20. Kalra RR, Kestle JR (2013) An assessment of academic productivity in pediatric neurosurgery. J Neurosurg Pediatr 12:262-265

21. Aoun SG, Bendok BR, Rahme RJ, Dacey RG Jr, Batjer HH (2013) Standardizing the evaluation of scientific and academic performance in neurosurgery-critical review of the "h" index and its variants. World Neurosurg 80:e85-e90

22. Spearman CM, Quigley MJ, Quigley MR, Wilberger JE (2010) Survey of the $\mathrm{h}$ index for all of academic neurosurgery: another power-law phenomenon? J Neurosurg 113:929-933

23. Lee J, Kraus KL, Couldwell WT (2009) Use of the h index in neurosurgery. Clinical article. J Neurosurg 111:387-392

24. Khan NR, Thompson CJ, Taylor DR, Gabrick KS, Choudhri AF, Boop FR, Klimo P Jr (2013) Part II: should the h-index be modified? An analysis of the m-quotient, contemporary hindex, authorship value, and impact factor. World Neurosurg 80:766-774

25. Hirsch JE (2005) An index to quantify an individual's scientific research output. Proc Natl Acad Sci U S A 102: $16569-16572$

26. Wilcox MA, Khan NR, McAbee JH, Boop FA, Klimo P Jr (2013) Highly cited publications in pediatric neurosurgery. Child Nerv Syst ChNS Off J Int Soc Ped Neurosurg 29:2201-2213

27. Sayama H, Akaishi J (2012) Characterizing interdisciplinarity of researchers and research topics using web search engines. PLoS One 7:e38747

28. Egger M, Smith GD (1998) Bias in location and selection of studies. BMJ 316:61-66

29. Kondziolka D (2013) Core journals. J Neurosurg 119:1271-1272, discussion 1272-1273 